\title{
Stroke and Coronary Artery Disease Are Associated With Parkinson's Disease
}

\author{
Qiongqiong Li, Cheng Wang, Huidong Tang, Shengdi Chen, Jianfang Ma
}

\begin{abstract}
Background: The relationship between vascular disease and Parkinson's disease (PD) is controversial. We performed a cross-sectional study to investigate the association of two common vascular diseases (stroke and coronary artery disease [CAD]) with Parkinson's disease. Methods: We identified 63 and 62 PD cases in two population-based cohorts (Malu rural community and Wuliqiao urban community) and collected information of PD and non-PD by means of questionnaires. Logistic regression analysis was used to investigate the association between stroke, coronary artery disease and PD, after adjusting for age, sex, hypertension, diabetes mellitus, hypercholesterolemia, smoking status, alcohol consumption, tea consumption and body mass index. Results: After adjustment for potential confounders, we found that CAD and stroke were associated with PD in the Malu rural community $(\mathrm{CAD}$ : odds ratio $[\mathrm{OR}]=7.11,95 \%$ confidence intervals [CI]: 3.09-16.40, $p<0.001$; stroke: $\mathrm{OR}=6.77,95 \% \mathrm{CI}: 3.09-14.81, p<0.001)$ and stroke was associated with PD in the Wuliqiao urban community $(\mathrm{OR}=2.58,95 \% \mathrm{CI}: 1.36-4.89, p=0.004)$, especially in women. In a subgroup analysis of PD with ageand sex-matched controls, the results were similar in the Malu rural community (CAD: $\mathrm{OR}=12.72,95 \% \mathrm{CI}: 2.92-55.32, p=0.001$; stroke: $\mathrm{OR}=6.26,95 \% \mathrm{CI}: 1.83-21.42, p=0.003$ ), whereas in the Wuliqiao urban community the results were different in that CAD (but not stroke) was found to be associated with PD (CAD: OR =2.44, 95\% CI: 1.09-5.47, $p=0.03$; stroke: OR =1.79, 95\% CI: 0.77-4.17, $p=0.18)$. Conclusions: Our study suggested that stroke and CAD are associated with PD in two Chinese population-based cohorts, indicating a probable vascular component in the pathogenesis of PD.
\end{abstract}

RÉSUMÉ: Les accidents vasculaires cérébraux et les coronaropathies peuvent être associés à la maladie de Parkinson. Contexte: Le lien unissant les maladies coronariennes et la maladie de Parkinson (MP) demeure controversé. Nous avons ainsi mené une étude transversale afin d'explorer l'association entre deux affections vasculaires fréquentes (les AVC et les coronaropathies) et la MP. Méthodes: C'est en Chine, plus précisément à Malu, une communauté rurale, et à Wuliqiao, une agglomération urbaine, que nous avons identifié 63 et 62 cas de MP constituant ainsi deux cohortes. Au moyen de questionnaires, nous avons ensuite recueilli des données au sujet des patients atteints de la MP mais aussi au sujet d'individus non atteints par cette maladie. Nous avons utilisé une analyse de régression logistique afin d'explorer l'association existant entre les AVC, les coronaropathies et la MP après avoir tenu compte des facteurs suivants : l'âge, le sexe, l'hypertension, un diagnostic de diabète et d'hypercholestérolémie, le tabagisme, la consommation d'alcool et de thé ainsi que l'indice de masse corporelle. Résultats: Après correction liée à de potentiels facteurs parasites, nous avons constaté que les coronaropathies et les AVC étaient associés à la MP au sein de la communauté rurale de Malu (coronaropathies : $\mathrm{RC}=7,11$, IC $95 \%: 3,09-16,40, p<0,001$; AVC : RC = 6,77, IC 95 \%: 3,09-14,81, $p<0,001$ ). Du côté de Wuliqiao, on a noté que les AVC étaient associés à la MP $(\mathrm{RC}=2,58$, IC $95 \%: 1,36-4,89, p=0,004)$, en particulier chez les femmes. Dans le cas d'une analyse par sous-groupe de l'incidence de la MP en tenant compte de témoins du même âge et du même sexe, les résultats se sont avérés semblables au sein de la communauté rurale de Malu (coronaropathies : $\mathrm{RC}=12,72$, IC $95 \%: 2,92-55,32, p=0,001$; AVC $: \mathrm{RC}=6,26$, IC 95 \% :1,83-21,42, $p=0,003$ ). Cela dit, les résultats ont différé dans la population de Wuliqiao en ce qui regarde les coronaropathies, et non les AVC, en lien avec la MP (coronaropathies : RC $=2,44$, IC $95 \%: 1,09-5,47, p=0,03$; AVC : RC = 1,79, IC $95 \%: 0,77-4,17, p=0,18)$. Conclusions: Notre étude suggère donc que les AVC et les coronaropathies étaient associés à la MP au sein de ces deux cohortes établies en Chine, ce qui indique une probable composante vasculaire dans la pathogénèse de la MP.

Keywords: Parkinson's disease, Stroke, Coronary artery disease, Vascular risk factor doi:10.1017/cjn.2018.56

Can J Neurol Sci. 2018; 45: 559-565

\section{INTRODUCTION}

Parkinson's disease (PD), clinically characterized by bradykinesia, rigidity, resting tremor and impaired postural stability, is the second most common neurodegenerative disease in the elderly. Along with the rapid aging of our population, the number of PD cases has increased gradually.

Stroke and coronary artery disease (CAD, including angina and myocardial infarction) are two common vascular diseases involving cerebral and coronary artery. However, the relationship of stroke and CAD with PD remains unclear. Some, ${ }^{1-4}$ but not all, ${ }^{5}$ epidemiological studies showed that vascular risk factors (e.g., diabetes, hypertension and increase in total cholesterol) were associated with an increased risk of PD. Small cerebral vessel diseases were found to be associated with mild parkinsonian signs. ${ }^{6-8}$ Rapid eye movement (REM) sleep behavior disorder,

From the Department of Neurology \& Institute of Neurology, Ruijin Hospital Affiliated to Shanghai Jiaotong University School of Medicine, Shanghai, China.

Received March 2, 2018. Final Revisions Submitted March 23, 2018. Date of ACCEPTANCE March 29, 2018.

Correspondence to: Jianfang Ma, Department of Neurology \& Institute of Neurology, Ruijin Hospital Affiliated to Shanghai Jiaotong University School of Medicine, No 197 Ruijin 2nd Road, Shang Hai, China. Email: majifa@hotmail.com 
one of the common non-motor symptoms of PD, was shown to increase the risk of stroke in a community-based study. ${ }^{9}$ These findings suggest a possible link between stroke and PD. Furthermore, cardiovascular dysautonomia was sometimes presented as another non-motor PD symptom and may occur early before motor dysfunction. ${ }^{10,11}$ The possible mechanism of cardiovascular dysautonomia in PD was loss of cardiac sympathetic innervations owing to dorsal vagal nucleus degeneration. ${ }^{12}$ These findings also suggest that CAD might be linked to PD through shared vascular risk factors and cardiac sympathetic denervation. We thus performed a community-based cross-sectional study in order to investigate whether stroke and CAD are associated with idiopathic PD in China.

\section{SubJects ANd Methods}

\section{Study Population and PD Ascertainment}

This two-step door-to-door study was conducted in two communities: Malu rural community from April to October 2013 and Wuliqiao urban community in 2014. The Malu rural community of Jiading district is located in the north-west rural area of Shanghai. The target population was 24,464 residents aged 50 years or older living in this area from community registry offices. ${ }^{13}$ The Wuliqiao urban community of Luwan district is located downtown, and the target population was 3970 permanent residents who were recruited in our sleep and dementia cohort established in 2009 and followed up in 2011 and 2014. ${ }^{14,15}$

In the first step, local doctors from medical centers of Malu and Wuliqiao community had a 1-day clinical teaching course on the evaluation of parkinsonism and essential tremor conducted by movement disorders specialists from the Department of Neurology, Rui Jin Hospital affiliated to Shanghai Jiao Tong University School of Medicine. This clinical teaching course included video presentation of symptoms of parkinsonism and essential tremor and how to retrieve the history. Under the supervision of the movement disorder specialist, the local doctor was considered qualified when they demonstrated competency to conduct the clinical examination of tremor, bradykinesia, rigidity and gait. After being trained, these local doctors visited residents aged $\geq 50$ years from door to door and reported possible parkinsonism cases to the movement disorder specialists. In the second step, movement disorder specialists revisited these possible parkinsonism cases to make the final diagnosis. The diagnostic procedure included medical record review, neurological examinations, imaging review if possible and so on (Figures 1 and 2). The diagnosis of PD patients was based on the United Kingdom Parkinson's Disease Society Brain Bank Clinical Diagnostic Criteria. This study was approved by the Ethical Committee of Rui Jin Hospital, with receipt of consent forms from each participant.

\section{Assessment of Coronary Artery Disease and Other Potential Cofounders}

Parkinson's disease patients and non-PD individuals willing to enter our study in the same suburb completed a questionnaire including the following information: history of CAD (yes/no), gender (female or male), age (year), weight (kilogram), height (centimeters), diabetes mellitus (yes/no), hypertension (yes/no), history of stroke (yes/no), hypercholesterolemia (yes/no), tea consumption (yes/no), smoking status (never/past smoker/current smoker: cigarettes/day, $1-19$ or $\geq 20$ ) and alcohol consumption (no/current: g/day, 0-9.99 or 10-19.99 or $\geq 20$ ). Body mass index (BMI) was calculated as weight in kilograms divided by height in meters squared and grouped into four categories in the analysis (BMI: $<18.5$ or $18.5-23.9$ or $24-26.9$ or $\geq 27 \mathrm{~kg} / \mathrm{m}^{2}$ ).

History of stroke and CAD was obtained by self-reporting. To increase the accuracy of diagnosis, we also recorded the hospital where the diagnosis of stroke and CAD was made and whether they saw a specialist for the diagnosis of stroke and CAD in hospitals. In the Wuliqiao community, 175 cases $(36.5 \%)$ of CAD and 120 cases $(35.1 \%)$ of stroke were diagnosed in third-grade class-A hospital (a high-level hospital evaluated by National Health Commission), and 302 cases $(62.9 \%)$ of CAD and 220 cases $(64.1 \%)$ of stroke were diagnosed in second-grade class-A hospitals (a middle-level hospital evaluated by National Health Commission). In the Malu community, more than $50 \%$ of CAD and stroke cases were diagnosed by specialists: 23 cases $(24.5 \%)$ of CAD and 24 cases $(24.2 \%)$ of stroke were diagnosed in third-grade class-A hospitals, and 38 cases $(40.4 \%)$ of CAD and 30 cases $(30.3 \%)$ of stroke were diagnosed in second-grade class-A hospitals.

\section{Statistical Analysis}

All analyses were conducted with SPSS, version 19 for Windows (SPSS Inc., Chicago, IL, USA). The characteristics of the study population (non-PD and PD) were compared by using the $\chi^{2}$ test for categorical variables and Student's $t$-test for continuous variables. For examining potential risk and protective factors for PD, we used multiple logistic regression models to calculate odds ratios (OR) and 95\% confidence intervals (CI), adjusting for age, sex, smoking status, alcohol consumption, hypertension, diabetes mellitus, tea consumption, hypercholesterolemia and BMI.

\section{RESULTS}

In the first step, 19,614 out of 24,464 residents (responding rate $=80.2 \%$ ) participated in the door-to-door interview in Malu community. A total of 124 possible PD cases were identified by local doctors. In the second step, movement disorder specialists finally confirmed the diagnosis of 97 PD patients. Among them, 63 PD patients completed the questionnaire and 34 PD patients did not complete the questionnaire for reasons such as hearing problem, unwillingness and so on (Figure 1). A total of 4483 non-PD residents from our previous dementia cohort in Malu community were included as controls and completed the questionnaire. ${ }^{16}$ For the Wuliqiao community, 3622 out of 3970 residents (responding rate $=91.2 \%$ ) were interviewed door-todoor and completed the questionnaire. A total of 69 possible PD cases were identified by local doctors and 62 cases were confirmed by movement disorder specialists (Figure 2). The remaining 3553 non-PD residents were included as controls in the association study. The demographic features of PD and non-PD population are listed in Table 1 .

We found that history of stroke was associated with the risk of PD both in Malu rural community $(\mathrm{OR}=6.77,95 \% \mathrm{CI}$ : 3.09 $14.81, p<0.001)$ and the Wuliqiao Urban community $(\mathrm{OR}=$ 2.58, 95\% CI: 1.36-4.89, $p=0.004$ ), after adjustment for age, sex, smoking status, alcohol consumption, tea consumption, hypertension, diabetes mellitus, hypercholesterolemia and BMI (Table 2). The association of stroke and PD was consistent in the female population of Malu rural $(\mathrm{OR}=4.03,95 \% \mathrm{CI}$ : $1.08-15.04$, 


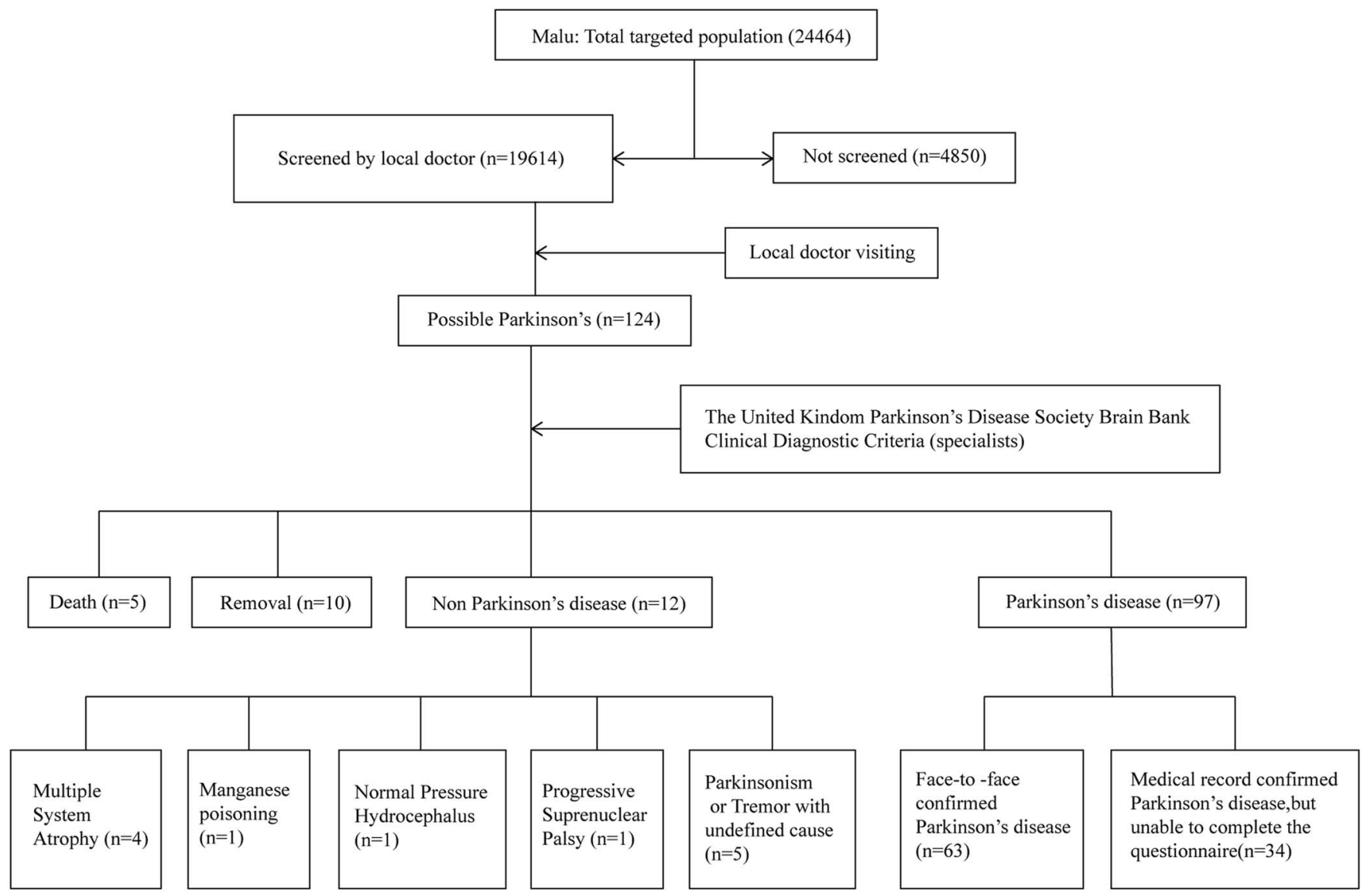

Figure 1: Flowchart of the Malu rural study.

$p=0.04)$ and Wuliqiao urban communities $(\mathrm{OR}=3.15,95 \% \mathrm{CI}$ : $1.34-7.42, p=0.009)$. However, for the male population, only Malu rural community found the positive association of stroke with $\mathrm{PD}(\mathrm{OR}=10.06,95 \%$ CI: 3.46-29.26) (Table 2).

In addition, history of CAD was associated with PD in Malu rural community $(\mathrm{OR}=7.11,95 \% \mathrm{CI}$ : 3.09-16.40, $p<0.001)$, after adjustment for age, sex, smoking status, alcohol consumption, tea consumption, hypertension, diabetes mellitus, hypercholesterolemia and BMI (Table 2). There was also a trend of association of history of CAD with PD in Wuliqiao urban community $(\mathrm{OR}=1.72,95 \% \mathrm{CI}: 0.91-3.23, p=0.09)$, especially in the male population ( $\mathrm{OR}=2.32,95 \% \mathrm{CI}$ : $0.91-5.98, p=0.08)$. To eliminate the possible cardiovascular effects of levodopa and dopamine receptor agonist, ${ }^{17}$ we restricted to PD patients without levodopa or dopaminergic agonist treatment (referred to as "drug-naïve PD cases" in the manuscript). As 34 cases of drugnaïve PD cases were found in the Malu community and only four cases in the Wuliqiao community, we only performed this analysis in the Malu rural community and the result was similar (Table 2). As the age of the individuals in the PD group was much higher than that of controls (Table 1), we performed the analysis again in an age-matched control group in both cohorts. We used PD and control group at a ratio of 1:3, matched for age, sex, hypertension, diabetes and hypercholesterolemia for individuals $<90$ years old, and a ratio of 1:1, matched for age and sex, for individuals $\geq 90$ years old (not enough controls available). The results are similar to those of the whole Malu community (CAD: $\mathrm{OR}=12.72,95 \% \mathrm{CI}: 2.92-55.32, p=0.001$; stroke: $\mathrm{OR}=6.26,95 \% \mathrm{CI}: 1.83-21.42, p=0.003)$, after adjustment for age, sex, smoking status, alcohol consumption, tea consumption, hypertension, diabetes mellitus, hypercholesterolemia and BMI. In the Wuliqiao community, CAD was found to be associated with PD (OR $=2.44,95 \%$ CI: 1.09-5.47, $p=0.03)$, whereas stroke was not $(\mathrm{OR}=1.79,95 \% \mathrm{CI}$ : 0.77 $4.17, p=0.18$ ), after adjustment for age, sex, smoking status, alcohol consumption, tea consumption, hypertension, diabetes mellitus, hypercholesterolemia and BMI, which is different from the whole Wuliqiao population.

We also found that tea consumption was significantly lower in PD groups than in controls in Malu community (17.5\% vs. $33.7 \%$, $p=0.007)$, but not in the Wuliqiao community (58.1\% vs. $68.1 \%$, $p=0.09$ ). Smoking consumption was significantly higher in PD groups than in controls in the Malu community $(p=0.04)$, but not in the Wuliqiao community. There was no significant difference with regard to hypertension, diabetes, hypercholesterolemia and BMI, between PD and non-PD groups.

\section{Discussion}

Our study found that individuals with stroke were more likely to have PD, which was consistent with some $e^{7,18-20}$ but not all previous studies. ${ }^{21,22}$ Interestingly, increased risk of stroke was also found in PD in a recent community-based study. ${ }^{19}$ Cerebral smallvessel disease was shown to be associated with mild parkinsonian 


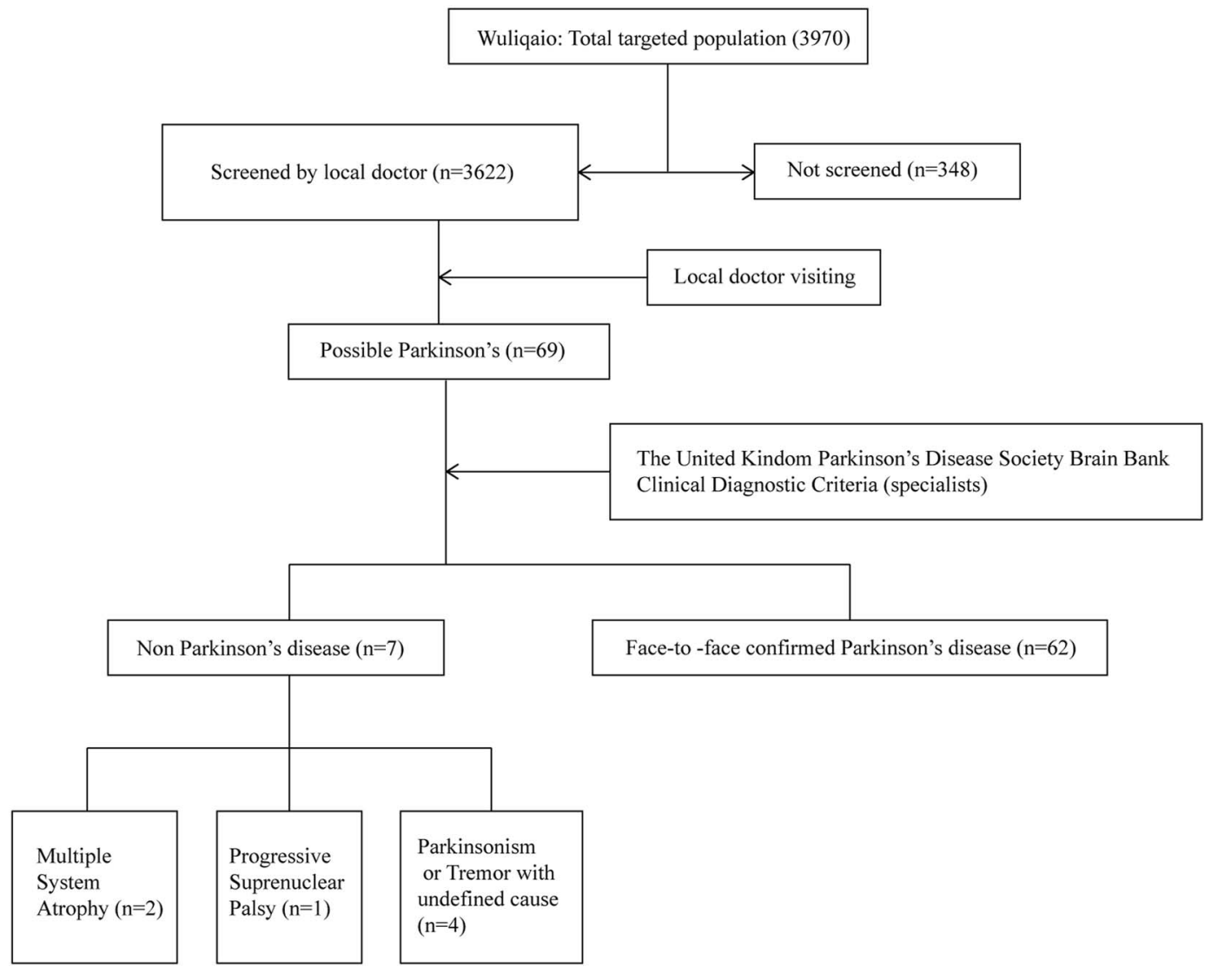

Figure 2: Flowchart of the Wuliqiao urban study.

signs in several cohorts. Vessel lesions in certain locations were suggested, accounting for the link between stroke and PD, including frontal and parietal white matter lesion or lacunar infarcts in the thalamus. ${ }^{6-8}$ Recently, small cerebral vascular changes such as microbleeds were also found to be associated with idiopathic PD. ${ }^{23}$ DJ-1, a gene causing familial PD, was shown to be involved in cerebral ischemia changes in in vitro and in vivo models, indicating another possible mechanism linking PD and stroke. ${ }^{24,25}$ However, neuropathological studies showed an inverse association of vascular lesions with PD lesions in the brains of autopsy-proven PD cases or dementia with Lewy bodies. ${ }^{21,26}$ Therefore, more studies will be needed to further investigate the association between stroke and PD and to reveal the underlying mechanisms.

We also found that history of CAD might be associated with an increased risk of $\mathrm{PD}$, independent of traditional risk factors such as age, male sex and smoking. Our finding was consistent with Liang's study, which showed an increased risk of acute myocardial infarction in PD (hazard ratios $=1.46) .{ }^{27}$ One possible explanation is that these two diseases share a common pathogenesis mechanism. Diabetes, hypertension and hypercholesterolemia were found to be associated with $\mathrm{PD}$ and CAD in epidemiological studies. ${ }^{1-3,28}$ It was possible that these vascular risk factors might contribute to PD and CAD through the same mechanisms. Another explanation for the relationship between CAD and PD is cardiac sympathetic denervation in PD. Cardiac sympathetic nerve is quite sensitive to ischemia. ${ }^{29}$ Chronic cardiac sympathetic denervation might aggravate the cardiac ischemia by sustained elevation of end-diastolic pressure after ischemia. ${ }^{30}$ In PD with orthostatic hypotension, chronic hypotension might result in exaggerated response to exogenously given adrenergic receptor agonists, a phenomenon called "denervation supersensitivity".31,32 Thus, it is possible that cardiac sympathetic denervation contributes to the risk of CAD by aggravating the damage to myocardial ischemia through abnormal pressure change after ischemia. Certainly, more studies need to be performed to confirm this assumption in the future.

Although anti-parkinsonian medications such as levodopa were found to exert cardiovascular side effects, our further analysis including only PD without levodopa or dopamine receptor agonist revealed similar results. These findings suggested that the association of PD and CAD was not mediated by medication such as levodopa or dopamine agonist. However, as the sample size of drug-naïve PD cases was extremely small, the results should be read cautiously.

Caffeine consumption and smoking were shown to be protective for PD in various epidemiological studies. ${ }^{33,34}$ In our study, tea consumption was lower in PD groups than in controls in both cohorts, but only reached statistical significance in the Malu community. However, smoking consumption was significantly higher in PD groups than in controls in the Malu community, but not in the Wuliqiao community. The negative or even inverse findings might be attributed to the small sample size, methodological difference and so on.

The strengths of our study are a door-to-door survey avoiding referral bias and PD diagnosis by movement disorders specialists. However, there are still some limitations. First, there were only 
Table 1: Demographic features of Parkinson's disease (PD) and non-PD cases

\begin{tabular}{|c|c|c|c|c|c|c|}
\hline & \multicolumn{3}{|c|}{ Malu rural district } & \multicolumn{3}{|c|}{ Wuliqiao urban district } \\
\hline & PD $(n=63)$ & Non-PD $(n=4483)$ & $p$ value & PD $(n=62)$ & $\begin{array}{c}\text { Non-PD } \\
(n=3553)\end{array}$ & $p$ value \\
\hline Age (years, mean \pm SD) & $74.90 \pm 8.60$ & $66.48 \pm 9.38$ & $<0.001 *$ & $75.73 \pm 9.48$ & $69.39 \pm 10.58$ & $<0.001 *$ \\
\hline $\operatorname{Sex}(n, \%)$ & & & 0.07 & & & 0.09 \\
\hline Men & $34(54.0)$ & $1906(42.5)$ & & $26(41.9)$ & $1134(31.9)$ & \\
\hline Women & $29(46.0)$ & $2577(57.5)$ & & $36(58.1)$ & $2419(68.1)$ & \\
\hline Diabetes $(n, \%)$ & $4(6.3)$ & $421(9.4)$ & 0.40 & $11(17.7)$ & $631(17.8)$ & 0.99 \\
\hline Hypertension $(n, \%)$ & $37(58.7)$ & $2050(45.7)$ & $0.04 *$ & $31(50.0)$ & $1675(47.1)$ & 0.66 \\
\hline Hypercholesterolemia $(n, \%)$ & $3(4.8)$ & $122(2.7)$ & 0.33 & $4(6.5)$ & $452(12.5)$ & 0.18 \\
\hline Stroke $(n, \%)$ & $10(15.9)$ & $89(2.0)$ & $<0.001 *$ & $14(22.6)$ & $328(9.2)$ & $<0.001 *$ \\
\hline $\mathrm{CAD}(n, \%)$ & $9(14.3)$ & $85(1.9)$ & $<0.001 *$ & $14(22.6)$ & $466(13.1)$ & $0.03 *$ \\
\hline Tea consumption $(n, \%)$ & $11(17.5)$ & $1512(33.7)$ & $0.007 *$ & $36(58.1)$ & $2419(68.1)$ & 0.09 \\
\hline Smoking status $(n, \%)$ & & & $0.04 *$ & & & 0.12 \\
\hline Never & $48(76.2)$ & $3611(80.5)$ & & $50(80.6)$ & $2803(78.9)$ & \\
\hline Past smoker & $0(0.0)$ & 205 (4.6) & & $6(9.7)$ & $189(5.3)$ & \\
\hline Current smoker (1-19 cigarettes/day) & $9(14.3)$ & $300(6.7)$ & & $2(3.2)$ & $361(10.2)$ & \\
\hline Current smoker ( $\geq 20$ cigarettes/day) & $6(9.5)$ & $367(8.2)$ & & $4(6.5)$ & $200(5.6)$ & \\
\hline Alcohol consumption $(n, \%)$ & & & 0.06 & & & 0.59 \\
\hline No & $60(95.2)$ & $3698(82.5)$ & & $59(95.2)$ & $3300(92.9)$ & \\
\hline $0-9.99 \mathrm{~g} / \mathrm{day}$ & $0(0.0)$ & $82(1.8)$ & & $3(4.8)$ & $123(3.5)$ & \\
\hline $10-19.99 \mathrm{~g} /$ day & $0(0.0)$ & $117(2.6)$ & & $0(0)$ & $44(1.2)$ & \\
\hline$\geq 20$ g/day & $3(4.8)$ & $586(13.1)$ & & $0(0)$ & $86(2.4)$ & \\
\hline Body mass index $(n, \%)$ & & & 0.14 & & & 0.99 \\
\hline$<18.5$ & $176(4.0)$ & $6(9.7)$ & & $5(8.1)$ & $292(8.2)$ & \\
\hline $18.5-23.9$ & $2143(48.9)$ & 27 (43.5) & & $31(50.0)$ & $1699(47.8)$ & \\
\hline $24-26.9$ & 1385 (31.6) & $18(29.0)$ & & $17(27.4)$ & $1007(28.3)$ & \\
\hline$\geq 27$ & $677(15.5)$ & $11(17.7)$ & & $9(14.5)$ & $555(15.6)$ & \\
\hline
\end{tabular}

$\mathrm{CAD}=$ coronary artery disease.

$* p<0.05$.

159 confirmed PD patients (97 from Malu and 62 from Wuliqiao) found in our door-to-door study. Estimated prevalence of PD in Shanghai elderly $\geq 50$ years older will be $0.5 \%$ in the rural community and $1.7 \%$ in the urban community, which was quite low compared with other epidemiological studies for the rural community. ${ }^{35}$ Although we trained the local doctors to screen PD patients, there is a high possibility that they lost some PD patients, especially for rural local doctors. Second, history of stroke and CAD was obtained by self-reporting. There might be some inaccuracy in the information provided by self-reporting history. More than $90 \%$ of CAD and stroke cases in the Wuliqiao community were diagnosed by specialists and more than $50 \%$ of CAD and stroke cases in the Malu community were diagnosed by specialists, indicating a comparable reliability of CAD and stroke diagnosis in our cohorts. However, self-recollected information of CAD might render a recall bias, as well as an understanding of the different diagnosis and educational levels, which may play an important role in our results. Third, our study was retrospective and performed in Chinese Shanghai area, and thus the results represent the population in Shanghai.
In conclusion, we found that history of stroke and CAD was associated with PD in two Chinese population-based cohorts. These findings suggest that vascular disease might play some role in the pathogenesis of PD. Therefore, it is still important to investigate the mechanism linking stroke and CAD with PD, and probably prevent or treat PD by modifying vascular factors in the future.

\section{ACKNOWLEDGMents}

This study was supported by National Key R\&D Program of China (2016YFC1306000). The authors thank Dr. Lifang Zhu, Dr. Yanqing Lu and all other doctors from Malu Medical Center for their support of our epidemiology study.

\section{Disclosures}

QL, HT, SC and JM received the grant from National Key R\&D Program of China (grant no. 2016YFC1306000). CW has nothing to disclose. 
Table 2: Multivariate regression results for the association between coronary artery diseases (CAD), stroke and risk of having Parkinson's disease (PD)

\begin{tabular}{|c|c|c|c|c|}
\hline & \multicolumn{2}{|c|}{ Malu rural community } & \multicolumn{2}{|c|}{ Wuliqiao urban community } \\
\hline & OR $(95 \% \mathrm{CI})$ & $p$ Value & OR $(95 \%$ CI $)$ & $p$ Value \\
\hline \multicolumn{5}{|l|}{ Stroke } \\
\hline Multivariate adjusted $\mathrm{OR}^{*}$ & $6.77(3.09-14.81)$ & $<0.001 * * *$ & $2.58(1.36-4.89)$ & $0.004 * * *$ \\
\hline Male subgroup & $10.06(3.46-29.26)$ & $<0.001 * * *$ & $1.93(0.73-5.13)$ & 0.19 \\
\hline Female subgroup & $4.03(1.08-15.04)$ & $0.04 * * *$ & $3.15(1.34-7.42)$ & $0.009^{* * *}$ \\
\hline Multivariate adjusted OR** & $8.09(2.97-22.04)$ & $<0.001$ & & \\
\hline \multicolumn{5}{|l|}{ CAD } \\
\hline Multivariate adjusted $\mathrm{OR}^{*}$ & $7.11(3.09-16.40)$ & $<0.001 * * *$ & $1.72(0.91-3.23)$ & 0.09 \\
\hline Male subgroup & $9.60(2.71-34.00)$ & $<0.001 * * *$ & $2.33(0.91-5.98)$ & 0.08 \\
\hline Female subgroup & $4.44(1.23-16.07)$ & $0.02^{* * *}$ & $1.38(0.58-3.31)$ & 0.47 \\
\hline Multivariate adjusted $\mathrm{OR}^{* *}$ & $9.62(3.43-27.00)$ & $<0.001 * * *$ & & \\
\hline
\end{tabular}

$\mathrm{OR}=$ odds ratio; $\mathrm{CI}=$ confidence intervals.

*Adjusted for age, sex, smoking status, alcohol consumption, tea consumption, hypertension, diabetes mellitus, hypercholesterolemia and body mass index.

**PD cases with no medication.

$* p<0.05$.

\section{Statement of Authorship}

QL collected data, performed the statistical analysis and drafted the manuscript. CW helped to collect data. HT made the diagnosis of PD. SC double-checked the diagnosis of PD. JM designed the study, double-checked the statistical analysis and revised the manuscript.

\section{REFERENCES}

1. Hu G, Antikainen R, Jousilahti P, Kivipelto M, Tuomilehto J. Total cholesterol and the risk of Parkinson disease. Neurology. 2008;70 (21):1972-9.

2. Qiu C, Hu G, Kivipelto M, et al. Association of blood pressure and hypertension with the risk of Parkinson disease: the National FINRISK Study. Hypertension. 2011;57(6):1094-100.

3. Xu Q, Park Y, Huang X, et al. Diabetes and risk of Parkinson's disease. Diabetes Care. 2011;34(4):910-5.

4. Jain S, Ton TG, Perera S, et al. Cardiovascular physiology in premotor Parkinson's disease: a neuroepidemiologic study. Mov Disord. 2012;27(8):988-95.

5. Simon KC, Chen H, Schwarzschild M, Ascherio A. Hypertension, hypercholesterolemia, diabetes, and risk of Parkinson disease. Neurology. 2007;69(17):1688-95.

6. Hatate J, Miwa K, Matsumoto M, et al. Association between cerebral small vessel diseases and mild parkinsonian signs in the elderly with vascular risk factors. Parkinsonism Relat Disord. 2016;26:29-34.

7. de Laat KF, van Norden AG, Gons RA, et al. Cerebral white matter lesions and lacunar infarcts contribute to the presence of mild parkinsonian signs. Stroke. 2012;43(10):2574-9.

8. Reitz C, Trenkwalder C, Kretzschmar K, Roesler A, Von Eckardstein A, Berger K. Relation of cerebral small-vessel disease and brain atrophy to mild Parkinsonism in the elderly. Mov Disord. 2006; 21(11):1914-9.

9. Ma C, Pavlova M, Liu Y, et al. Probable REM sleep behavior disorder and risk of stroke: a prospective study. Neurology. 2017;88(19):1849-55.

10. Goldstein DS. Dysautonomia in Parkinson's disease: neurocardiological abnormalities. Lancet Neurol. 2003;2(11):669-76.

11. Chen H, Zhao EJ, Zhang W, et al. Meta-analyses on prevalence of selected Parkinson's nonmotor symptoms before and after diagnosis. Transl Neurodegener. 2015;4(1):1.
12. Braak H, Ghebremedhin E, Rub U, Bratzke H, Del Tredici K. Stages in the development of Parkinson's disease-related pathology. Cell Tissue Res. 2004;318(1):121-34.

13. Ma JF, Hou MM, Tang HD, et al. REM sleep behavior disorder was associated with Parkinson's disease: a community-based study. BMC Neurol. 2016;16:123.

14. Zhuang JP, Wang G, Cheng Q, et al. Cognitive impairment and the associated risk factors among the elderly in the Shanghai urban area: a pilot study from China. Transl Neurodegener. 2012;1(1):22.

15. Ma JF, Qiao Y, Gao X, et al. A community-based study of risk factors for probable rapid eye movement sleep behavior disorder. Sleep Med. 2017;30:71-6.

16. Tang HD, Zhou Y, Gao X, et al. Prevalence and risk factor of cognitive impairment were different between urban and rural population: a community-based study. J Alzheimers Dis. 2016;49 (4):917-25.

17. Noack C, Schroeder C, Heusser K, Lipp A. Cardiovascular effects of levodopa in Parkinson's disease. Parkinsonism Relat Disord. 2014;20(8):815-8.

18. Becker C, Jick SS, Meier CR. Risk of stroke in patients with idiopathic Parkinson disease. Parkinsonism Relat Disord. 2010;16 (1):31-5.

19. Huang YP, Chen LS, Yen MF, et al. Parkinson's disease is related to an increased risk of ischemic stroke-a population-based propensity score-matched follow-up study. PLoS One. 2013;8(9):e68314.

20. Patel M, Coutinho C, Emsley HC. Prevalence of radiological and clinical cerebrovascular disease in idiopathic Parkinson's disease. Clin Neurol Neurosurg. 2011;113(10):830-4.

21. Ghebremedhin E, Rosenberger A, Rub U, et al. Inverse relationship between cerebrovascular lesions and severity of Lewy body pathology in patients with Lewy body diseases. J Neuropathol Exp Neurol. 2010;69(5):442-8.

22. Song IU, Kim YD, Cho HJ, Chung SW. The effects of silent cerebral ischemic lesions on the prognosis of idiopathic Parkinson's disease. Parkinsonism Relat Disord. 2013;19(8):761-3.

23. Kim JH, Park J, Kim YH, Ma HI, Kim YJ. Characterization of cerebral microbleeds in idiopathic Parkinson's disease. Eur J Neurol. 2015;22(2):377-83.

24. Kitamura Y, Watanabe S, Taguchi M, et al. Neuroprotective effect of a new DJ-1-binding compound against neurodegeneration in Parkinson's disease and stroke model rats. Mol Neurodegener. 2011;6(1):48 
25. Dongworth RK, Mukherjee UA, Hall AR, et al. DJ-1 protects against cell death following acute cardiac ischemia-reperfusion injury. Cell Death Dis. 2014;5:e1082.

26. Schwartz RS, Halliday GM, Cordato DJ, Kril JJ. Small-vessel disease in patients with Parkinson's disease: a clinicopathological study. Mov Disord. 2012;27(12):1506-12.

27. Liang HW, Huang YP, Pan SL. Parkinson disease and risk of acute myocardial infarction: a population-based, propensity score-matched, longitudinal follow-up study. Am Heart J. 2015;169(4):508-14.

28. Franklin SS, Gokhale SS, Chow VH, et al. Does low diastolic blood pressure contribute to the risk of recurrent hypertensive cardiovascular disease events? The Framingham Heart Study. Hypertension. 2015;65(2):299-305.

29. Guertner C, Klepzig H Jr., Maul FD, et al. Noradrenaline depletion in patients with coronary artery disease before and after percutaneous transluminal coronary angioplasty with iodine-123 metaiodobenzylguanidine and single-photon emission tomography. Eur J Nucl Med. 1993;20(9):776-82.
30. Lavallee M, Amano J, Vatner SF, Manders WT, Randall WC, Thomas JX Jr. Adverse effects of chronic cardiac denervation in conscious dogs with myocardial ischemia. Circ Res.. 1985; 57(3):383-92.

31. Senard JM, Valet P, Durrieu G, et al. Adrenergic supersensitivity in parkinsonians with orthostatic hypotension. Eur J Clin Invest. 1990;20(6):613-9.

32. Imrich R, Eldadah BA, Bentho O, et al. Functional effects of cardiac sympathetic denervation in neurogenic orthostatic hypotension. Parkinsonism Relat Disord. 2009;15(2):122-7.

33. Ma C, Liu Y, Neumann S, Gao X. Nicotine from cigarette smoking and diet and Parkinson disease: a review. Transl Neurodegener. 2017;6:18.

34. Ascherio A, Schwarzschild MA. The epidemiology of Parkinson's disease: risk factors and prevention. Lancet Neurol. 2016; 15(12):1257-72.

35. Zhang ZX, Roman GC, Hong Z, et al. Parkinson's disease in China: prevalence in Beijing, Xian, and Shanghai. Lancet. 2005; 365(9459):595-7. 